\title{
Effect of Rational-Emotive Distress Management Intervention on Work-Related Emotional Distress among Primary Healthcare Workers
}

\author{
Uchenna C. Ugwu ${ }^{1}$, Emmanuel K. Nwala ${ }^{3}$, Uchechukwu A. Ezugwu ${ }^{2} \&$ Nnagozie Chukwuebuka $^{1}$ \\ ${ }^{1}$ Department of Human Kinetics and Health Education, Faculty of Eduucation, University of Nigeria, Nsukka, \\ Enugu State, Nigeria \\ ${ }^{2}$ Department of Medical Rehabilitation, Faculty of Health Science and Technology, University of Nigeria, Enugu \\ Campus, Nigeria \\ ${ }^{3}$ Social Accountability and Governance Advisor, RTI International/ Health Policy Plus Project, Nigeria \\ Correspondence: Uchechukwu A. Ezugwu, Department of Medical Rehabilitation, Faculty of Health Science and \\ Technology, University of Nigeria, Enugu Campus, Nigeria. Tel: 234-803-691-0730.
}

Received: May17, 2020 Accepted: June 21, 2020 Online Published: July 14, 2020

doi:10.5539/gjhs.v12n10p1 URL: https://doi.org/10.5539/gjhs.v12n10p1

\begin{abstract}
Emotional distress is associated with irrational beliefs, psychopathological conditions, and maladaptive behaviors. The objective of this study was to investigate the effect of rational-emotive distress management intervention -REDMI on work-related emotional distress among primary healthcare workers -PHCWs in Nigeria. A pretest-posttest randomized control group design was adopted by the investigators. Using convenient sampling procedure, $52 \mathrm{PHCWs}$ were studied. These participants were assigned to either treatment $(\mathrm{n}=26)$ or control $(\mathrm{n}=26)$ groups respectively. Only the treatment group received rational-emotive distress management intervention. The profile of emotional distress $-\mathrm{PED}$ (internal consistency $=0.94$ ) was used for the pretest and posttest data collection. The IBM SPSS version 22 was employed for all statistical data analysis. The study participants in treatment group scored lower $(10.87 \pm 2.63)$ in the posttest measure when compared to pretest scores $(18.24 \pm 2.88)$. This implied that REDMI was effective in managing work-related emotional distress in a sample of primary healthcare workers in Nigeria. The REDMI is effective in managing work-related emotional distress among PHCWs in Nigeria. Professionals and experts in emotional health are therefore encouraged to adopt management intervention programs such as REDMI in helping workers and clients to manage emotional distress.
\end{abstract}

Keywords: emotional distress, rational-emotive distress management intervention, primary healthcare workers, effect, Nigeria

\section{Introduction}

Worldwide, emotional distress is common among workers (Nwikina \& Nwanekez, 2010; Ogungbamila, 2012; Olorunsola, 2013). Approximately 30 per cent of workers were reported to be affected by work-related emotional distress (Greiner, 2008). High level of emotional distress is associated with irrational beliefs, psychopathological conditions, and maladaptive behaviors (Turner \& Barker, 2013). It equally holds huge effect on the worker's job satisfaction and productivity level as well as emotional stability. Without doubts, irrational beliefs and thoughts aggravate increased vulnerability to emotional distress and have significant impact on distress among healthcare workers (Bernhardt, Rushton, \& Carrese, 2009). Categorically, emotional distress can be classified into dysfunctional and functional distress. While functional distress like sadness corresponds to conventional negative reactions to any form of stressful event, the dysfunctional distress corresponds to other important emotional health problems such as depression (DiLorenzo, David, \& Montgomery, 2011). The authors further explained that dysfunctional distress involving negative thoughts and maladaptive feelings usually precede functional distress as observed in depression involving sadness. In a nutshell, rational beliefs are related to functional distress, whereas irrational beliefs are related to dysfunctional distress (DiLorenzo, David, \& Montgomery, 2011; Mogoas, Stefan, \& David, 2013). Researchers therefore, maintained that irrational beliefs from the rational-emotive perspectives, sustain emotional distress (David \& Szamoskozi, 2011).

The consequences of rational beliefs may include adaptive, while that of irrational belief may involve maladaptive. However, both irrational and rational beliefs play important role in emotional distress prediction (Popov \& Popov, 
2013). Emotional distress can lead to disorders of the mood, depression and increased anxiety (David, Szentagotai, \& Lupu, 2008). This realization portrays the sole aim of intervention programs such as the present in helping workers to optimistically dispute irrational beliefs and attain adaptive beliefs (DiLorenzo, David, \&Montgomery, 2011; Ugwoke et al., 2017; Ogbuanya et al., 2018). Interventions are helpful to enable workers manage emotional distress and irrational beliefs (DiLorenzo, David, \& Montgomery, 2011). Work-related distress tends to increase the frequency of illness symptoms, absenteeism, productivity decline and high healthcare costs (Lazuras et al., 2009; David \& Szamoskozi, 2011).

The rational-emotive distress management intervention -REDMI is a validated programme specifically designed to manage emotional distress in a given population. The successful application of similar management interventions by researchers revealed its effectiveness in reducing and managing emotional distress (Adomeh, 2006; Richardson \& Rothstein, 2008). To the best of the researchers' knowledge, there is dearth literature on the interventions in managing work-related emotional distress in a sample of primary healthcare workers -PHCWs in Nigerian. Although, similar intervention studies abound in Nigerian context (e.g. Adomeh, 2006; Ugwoke et al., 2017), yet none seem to have focused on assisting PHCWs in managing work-related emotional distress. The results of previous studies were evidence that workers are vulnerable to work-related emotional distress (Adeniyi, 2010; Eze, 2017). It is the researchers' expectation that people's thinking pattern and feelings can be positively modified. Therefore, the objective of this study was to investigate the effect of REDMI on work-related emotional distress among PHCWs in Nigeria. The study also verified the null hypothesis that the REDMI would result in significant management of work-related emotional distress among PHCW in the treatment group compared to those in the control group.

\section{Method}

\subsection{Research Design}

A pretest-posttest randomized control group design was adopted by the investigators in accomplishing the purpose of this study. This was in line with the considerations of previous researchers in similar studies that the design is most appropriate for a study of this kind in their respective studies (Ugwoke et al., 2018; Ezenwaji et al., 2019).

\subsection{Recruitment of Participants and Procedures}

A convenient sampling procedure was used by the investigators in drawing a total of 52 primary healthcare workers from public health facilities in Nigeria between September 2019 and February 2020. Prior to the study, the investigators created awareness and sent information to the PHCWs in all the public health facilities in Nigeria, highlighting the need to conduct this study and possibly the eligibility of the potential participants. The investigators set inclusion criteria which must be met by the potential participants. These criteria include that a participant must have experienced work-related emotional distress in the workplace. Secondly, the individual must be eager to involve him/herself in the intervention program from the beginning till the finishing point. Finally, the participants must complete an informed consent form declaring the willingness to participate without any coercion. Out of 1,568 sampled primary healthcare workers, only 52 of them met the stipulated inclusion criteria and thus were recruited and used for the study. The 52 eligible participants were randomized to either treatment group $(\mathrm{N}=26)$ or control group $(\mathrm{N}=26)$ respectively based on the suggestions of previous researchers (Saghaei, 2014; Ugwoke et al., 2018; Ezenwaji et al., 2019). Only the study participants in the treatment group were exposed to rational-emotive distress management intervention with the sole target of alleviating work-related emotional distress while those in the control group completed only the profile emotional distress questionnaire. The REDMI manual which is written in English language was used for the implementation of the programme. The pretest and posttest measures were carried out separately using small group of six participants during the period of the intervention. The investigators completed the assignments of the study participants in order to eliminate selection or allocation bias. Data generated for both groups (treatment and control) and period (pretest and posttest) were blinded by the investigators until the statistical analysis was completed. This was done in order to control all potential risks and bias. All the participants were paid for participating in the study. Duration of two hours was allotted to each group session which lasted for a period of eight weeks in the chosen health facility as agree with the participants.

\subsection{Tool for Data Collection}

The research tool used for data collection was profile of emotional distress (PED) (Opris \& Macavei, 2007). The PED is a self-reported questionnaire that measures emotional distress of multiple dimensions. The study participants were requested to respond to the items of PED in a 5-point Likert-type scale. This tool allows investigators to code global score of emotional distress. Using the PED, the item that records high score indicates 
high level of emotional distress while low score reflects low level of emotional distress. Researchers had earlier shown that PED is a reliable tool with a convincing internal consistency (Cronbach's alpha $=0.94)$ (Opris \& Macavei, 2007).

\subsection{Statistics}

The investigators employed IBM SPSS version 22 for all statistical data analysis (IBM, 2013). All the statistical assumption and consideration were met. In the study, no data was found missing after a thorough data cross-check. In order to affirm the effect size of REDMI, analysis of variance (ANOVA) and t-test analysis were adopted. Also, adjusted R2 and partial eta squared (h2p) were recorded as well as confidence intervals of results. The pretest and posttest activities were successfully completed by the study participants. The outcomes of this research were deemed statistically significant at $\mathrm{P}=0.05$.

\subsection{Ethical Approval}

The approval for this research was obtained from the Research and Ethics Committee, University of Nigeria Teaching Hospital, ItukuOzalla, Enugu State of Nigeria. The ethical standard as stipulated by the American Psychological Association for conducting studies involving human organisms was judiciously observed by the researcher (American Psychological Association, 2017). This was also in accordance with the ethical considerations based on the principles of the World Medical Association's Declaration of Helsinki (World Medical Association, 2013).

\section{Results}

Table 1. Socio-demographic characteristics of primary healthcare workers $(\mathrm{N}=52)$

\begin{tabular}{|c|c|c|c|c|c|}
\hline Variables & & Treatment group N(\%) & Control group N(\%) & Stat. & Sig. \\
\hline \multirow{2}{*}{ Gender } & Male & $12(46 \%)$ & $15(58 \%)$ & \multirow{2}{*}{0.073} & \multirow{2}{*}{0.162} \\
\hline & Female & $14(54 \%)$ & $11(42 \%)$ & & \\
\hline \multirow{2}{*}{ YWE } & Less than 10 yrs & $15(58 \%)$ & $12(46 \%)$ & \multirow{2}{*}{0.830} & \multirow{2}{*}{0.009} \\
\hline & 10 yrs plus & $11(42 \%)$ & $14(54 \%)$ & & \\
\hline \multirow{2}{*}{ Location } & Urban & $11(42 \%)$ & $14(54 \%)$ & \multirow{2}{*}{.250} & \multirow{2}{*}{0.529} \\
\hline & Rural & $15(58 \%)$ & $12(46 \%)$ & & \\
\hline \multirow{2}{*}{ Age } & Below 30 years & $13(50 \%)$ & $12(46 \%)$ & \multirow{2}{*}{0.104} & \multirow{2}{*}{0.017} \\
\hline & 30 years plus & $13(50 \%)$ & $14(54 \%)$ & & \\
\hline \multirow{2}{*}{ Gender } & Male & $12(46 \%)$ & $15(58 \%)$ & \multirow{2}{*}{0.073} & \multirow{2}{*}{0.162} \\
\hline & Female & $14(54 \%)$ & $11(42 \%)$ & & \\
\hline \multirow{2}{*}{ YWE } & Less than $10 \mathrm{yrs}$ & $15(58 \%)$ & $12(46 \%)$ & \multirow{2}{*}{0.830} & \multirow{2}{*}{0.009} \\
\hline & 10 yrs plus & $11(42 \%)$ & $14(54 \%)$ & & \\
\hline \multirow{2}{*}{ Location } & Urban & $11(42 \%)$ & $14(54 \%)$ & \multirow{2}{*}{.250} & \multirow{2}{*}{0.529} \\
\hline & Rural & $15(58 \%)$ & $12(46 \%)$ & & \\
\hline \multirow{2}{*}{ Age } & Below 30 years & $13(50 \%)$ & $12(46 \%)$ & \multirow{2}{*}{0.104} & \multirow{2}{*}{0.017} \\
\hline & 30 years plus & $13(50 \%)$ & $14(54 \%)$ & & \\
\hline
\end{tabular}

Keys: Stat=statistic, $\mathrm{N}=$ sample size, $\%=$ percentage, Sig=significance, ()$=$ bracket sign, YWE=Years of Working experience, Yrs=years.

All the study participants were Nigerians with a total of 52 primary healthcare workers. Based on gender, the males were $12(46 \%)$ and the females were $14(54 \%)$ in the treatment group; and $15(58 \%)$ males and $11(42 \%)$ females in the non treatment group, with no significant difference $(0.05<0.162)$. According to years of working experience, $15(58 \%)$ of them had less than 10 years and $11(42 \%)$ had worked above 10 years as primary healthcare worker in the treatment group; and 12(46\%) of the them indicated less than 10 years and $14(54 \%)$ of the participants had above 10 years of working experience in the control group, with statistically significant difference $(0.05>0.009)$. Also, a total of $11(42 \%)$ participants were urban dwellers and $15(58 \%)$ were rural settlers in the treatment group; 
and $14(54 \%)$ urban-dwellers and $12(46 \%)$ rural settlers in the control group, with no statistically significant difference $(0.05<0.529)$. As regards to age, $13(50 \%)$ of the participants fall below 30 years of age and $13(50 \%)$ were 30 years and above in the treatment group; and 12(46\%) of them were below 30 years and 14(54\%) of the participants were 30 years and above in the control group, with statistically significant difference $(0.05>0.017)$. The attendance to all the group sessions by the participants was adequate and quite encouraging $(100 \%)$. In the study, there was no record of any form of physical, social or environmental harm or hazard during the intervention process (see Table 1).

Table 2. Showing results of the rational emotive distress management intervention on the PHCW $(\mathrm{N}=52)$

\begin{tabular}{|c|c|c|c|c|c|c|c|c|c|c|}
\hline Inst. & Period & Group & $\mathrm{M} \pm \mathrm{SD}$ & SE & $95 \%$ & CI & $\mathrm{F}$ & Sig. & $\mathrm{h} 2 \mathrm{p}$ & DR2 \\
\hline PED & \multirow{2}{*}{ Pre-T } & \multirow{2}{*}{ Treatment } & $18.24 \pm 2.88$ & 3.14 & $12.12-26$ & .142 & 3.021 & 0.151 & 0.201 & 0.613 \\
\hline Control & & & $17.03 \pm 2.92$ & 3.14 & $12.04-26$ & .361 & & & & \\
\hline PED & \multirow{2}{*}{ Post-T. } & \multirow{2}{*}{ Treatment } & $10.87 \pm 2.63$ & 2.02 & $18.121-16$ & .812 & 0.612 & 1.801 & 3.010 & 0.592 \\
\hline Control & & & $16.12 \pm 3.22$ & 2.02 & $15.232-12$ & .731 & & & & \\
\hline
\end{tabular}

PED $=$ profile emotional distress, DR2=adjusted R2, Inst=instrument, $\%=$ percentage, Post $-T=p o s t$ test,$h 2 p=$ partial eta squared, $S E=$ standard error, $C I=$ confidence interval, Pre-T $=$ pretest, mean $\pm S D=$ mean andstandard deviation.

Data in Table 2 showed that there was no significant difference between the participants in the treatment (18.24 \pm 2.88$)$ and control groups (17.03 \pm 2.92$)$ on PED pretest, $\mathrm{F}=3.021, \mathrm{P}=0.151, \mathrm{~h} 2 \mathrm{p}=0.201, \mathrm{DR} 2=0.613$, $\mathrm{SE}=3.14$. Also, the Table indicated that no statistically significant difference existed between the participants in the treatment $(10.87 \pm 2.63)$ and control groups $(16.12 \pm 3.22)$ on PED post test scores, $\mathrm{F}=0.612, \mathrm{P}=1.801, \mathrm{~h} 2 \mathrm{p}=3.010$, $\mathrm{DR} 2=0.592, \mathrm{SE}=2.02$. The data further showed that the study participants in treatment group scored lower $(10.87 \pm 2.63)$ in the posttest when compared to post test scores of those in the control groups $(16.12 \pm 3.22)$. However, there was obvious decline in post test PED scores when compared with the pretest PED scores of the study participants in the treatment group $(10.87 \pm 2.63<18.24 \pm 2.88)$. This implied that REDMI was effective in managing work-related emotional distress among primary healthcare workers in Nigeria (see Table 2).

\section{Discussion}

The purpose of this study was to investigate the effect of rational-emotive distress management intervention on work-related emotional distress among primary healthcare workers in Nigeria. At the pretest survey, all the study participants showed high level of work-related emotional distress based on the findings. This was in consistence with other findings which reported that workers are vulnerable to emotional distress in workplaces (Nwikina \& Nwanekez, 2010; Ogungbamila, 2012; Olorunsola, 2013). The result of posttest survey was quite encouraging as it justified the effectiveness of REDMI on work-related emotional distress of PHCWs in Nigeria. This was evidenced on the improved emotional exhaustion, cognitive weariness, and physical fatigue level of the participants in the treatment group compared to those in the non-treatment group. Also, it was found that REDMI was effective in managing work-related emotional distress among PHCWs in the intervention group compared to those in the non-intervention group. This finding was not surprising as it supports the reports of previous renowned scholars on interventions studies who revealed significant effect of similar interventions on distress and distress consequences (Adomeh, 2006; Richardson \& Rothstein, 2008; Popov \& Popov, 2013). The findings of this research have contributed to wealth of relevant empirical findings that intervention programs are indispensible in managing emotional distress among workers in the occupational setting.

High level of emotional distress can result to workers' poor job satisfaction, productivity decline and multiple emotional health problems including irrational beliefs, psychopathological conditions, and maladaptive behaviors (Turner \& Barker, 2013). The REDMI targets combating irrational beliefs and unhealthy negative emotions based on the suggested evidences (Beriman, 2007; Turner \& Barker, 2016). The implications of this study outcome may extend to public health educators, occupational health professionals, emotional and mental health experts, as well as behavioral medicine experts. These individuals can collaboratively develop effective intervention system for helping workers and potential clients to manage work-related emotional distress. The successful adoption of this intervention in occupational environment would be crucial in managing diverse forms of emotional distress among workers. This is necessary because the disputation of work-related irrational thoughts and beliefs would precipitate and enhance the adoption of rational and adaptive thoughts and invariably, the worker would be exonerated from emotional distress. 
The present research recorded some obvious limitations. Although, its strength lies in the proper adoption of methodology and design in establishing the effectiveness of REDMI on work-related emotional distress of PHCWs, there is need to address the common method-bias which occurred due to self-reported measures applied in this study. The data collection process purely relied on the use of PEM tool. Future research is needed to apply other data collection tools such as interview, and observations schedules. There is also need to conduct a follow-up study on this aspect. All the study participants were primary healthcare workers from Nigeria and therefore, this result cannot be generalized to PHCWs in other parts of the world. Thus, the need for future studies extending to PHCWs in other countries becomes necessary. In the present research, there is obvious concern about the use of small sample size. Future studies are encouraged to adopt larger sample participant as deemed necessary.

\section{Conclusion}

The present study attempted to investigate the effect of rational-emotive distress management intervention on work-related emotional distress among primary healthcare workers in Nigeria. The REDMI was effective in managing work-related emotional distress of PHCW at posttest survey of treatment group when compared to the pretest survey of same group. Also, the effectiveness of REDMI was evidenced on treatment group when compared to the control group in both measures of pretest and posttest. This therefore suggests that REDMI should be developed and implemented in all the occupational environments to enable workers manage work-related emotional distresses.

\section{Acknowledgments}

None to declare.

\section{Competing Interests Statement}

The authors declare that there was no competing or potential conflict of interest.

\section{References}

Adeniyi, S. O., Fakolade, O. A., \& Tella, A. (2010). Perceived causes of job stress among special educators in selected special and integrated schools in Nigeria. New Horizons Educ, 58, 73-82.

Adomeh, O. C. I. (2006). Fostering emotional adjustment among Nigerian adolescents with REBT. Educ Res $Q$, 29, 21-9.

American Psychological Association. (2017). Ethical Principles of Psychologists and Code of Conduct. Washington, DC.

Beriman, J. (2007). Can coaching combat distress at work? Occup Health, 59, 27-30.

Bernhardt, B. A., Rushton, C. H., Carrese, J., et al. (2009). Distress and burnout among genetic service providers. Genet Med,11, 527-35. https://doi.org/10.1097/GIM.0b013e3181a6a1c2

David, A. R., \& Szamoskozi, S. (2011). A meta-analytical study on the effects of cognitive behavioral techniques for reducing distress in organizations. J Cogn Behav Psychother, 11, 221-36.

David, D., Szentagotai, A., Lupu, V., et al. (2008). Rational emotive behavior therapy, cognitive therapy, and medication in the treatment of major depressive disorder: a randomized clinical trial, posttreatment outcomes, and six-month follow-up. J ClinPsychol, 64, 728-46. https://doi.org/10.1002/jclp.20487

DiLorenzo, T., David, D., \& Montgomery, G. H. (2011).The impact of general and specific rational and irrational beliefs on exam distress; a further investigation of the binary model of distress as an emotional regulation model. J Cogn Behav Psychother, 11, 121-42.

Eze, P. O. (2017). Effect of Rational Emotive Behavior Therapy on Work Stress of Special Educators in Enugu State. Nsukka, Nigeria: University of Nigeria, Postgraduate Diploma Thesis.

Ezenwaji, I. O., Eseadi, C., Ugwoke, S. C., Vita-Agundu, U. C., Edikpa, E., Okeke, F. C., \& Nwafor, B. N. (2019). A group-focused rational emotive behavior coaching for management of academic burnout among undergraduate students: Implications for school administrators. Medicine, 98, 30(e16352). https://doi.org/10.1097/MD.0000000000016352

Greiner, A. (2008). An economic model of work related distress. J Econ Behav Organ, 66, 335-46. https://doi.org/10.1016/j.jebo.2006.12.001

I.B.M. Corp. (2013). IBM SPSS Statistics for Windows, version 22. Armonk, NY: IBM Corp.

Lazuras, L., Rodafinos, G., Matsiggos, G, et al. (2009). Perceived occupational distress, affective, and physical 
well-being among telecommunication employees in Greece. Soc Sci Med, 68, 1075-1081. https://doi.org/10.1016/j.socscimed.2008.12.020

Mogoas, E., Stefan, S., \& David, D. (2013). How do we measure rational and irrational beliefs? the development of rational and irrational beliefs scale (RAIBS)_a new theory-driven measure. J CognBehavPsychother, 13, $529-46$.

Nwikina, L., \& Nwanekez, A. (2010).Management of job-related teacher burnout in Nigerian schools.Academia Arena, 2, 31-8.

Ogbuanya, T.C., Eseadi, C., Orji, C. T., et al. (2018). Effect of rational-emotive behavior therapy program on the symptoms of burnout syndrome among undergraduate electronics work students in Nigeria. Psychol Reports, 33294117748587. https://doi.org/10.1177/0033294117748587

Ogungbamila, B. (2012). Occupational burnout among employees in some service occupations in Nigeria: are health workers different? Psychol Thought, 6, 153-65. https://doi.org/10.5539/ijps.v6n3p71

Olorunsola, E. O. (2013). An appraisal of burnout among the University Lecturers in Ekiti State, Nigeria. $J$ Educ Develop Psychol, 3,133-137. https://doi.org/10.5539/jedp.v3n2p133

Opris, D., \& Macavei, B. (2007).The profile of emotional distress. J CognBehavPsychother, 7,139-59.

Popov, B., \& Popov, S. (2013). Adverse working conditions, job insecurity and occupational stress: the role of (Ir) rational beliefs. J Ration Emot Cogn Behav Ther, 31, 27-38. https://doi.org/10.1007/s10942-012-0157-5

Richardson, K., \& Rothstein, H. (2008). Effects of occupational distress management intervention programs: a meta-analysis. J Occup Health Psychol, 13, 69-93. https://doi.org/10.1037/1076-8998.13.1.69

Saghaei, M. (2014). Random Allocation Software [Computer Software]. Retrieved from http://mahmoodsaghaei.tripod.com/Softwares/randalloc.html

Turner, M. J., \& Barker, J. B. (2013). Examining the efficacy of rational-emotive behavior therapy (REBT) on irrational beliefs and anxiety in elite youth cricketers. $J$ Appl Sport Psychol, 25, 131-147. https://doi.org/10.1080/10413200.2011.574311

Turner, M. J., \& Barker, J. B. (2016). Rational emotive behavior therapy (REBT), irrational and rational beliefs, and the mental health of athletes. Front Psychol, 7, 1423.

Ugwoke, S. C., Eseadi, C., Igbokwe, C. C., et al. (2017). Effects of a rational-emotive health education intervention on stress management and irrational beliefs among technical college teachers in Southeast Nigeria. Medicine, 96, e7658.https://doi.org/10.1097/MD.0000000000007658

Ugwoke, S. C., Eseadi, C., Onuigbo, L. N., Aye, E. N., Akaneme, I. N., Oboegbulem, A. I., Ezenwaji, I. O. et al. (2018). A rational-emotive stress management intervention for reducing job burnout and dysfunctional distress among special education teachers: An effect study. Medicine, 97, 17(e0475). https://doi.org/10.1097/MD.0000000000010475

World Medical Association. (2013). Declaration of Helsinki Ethical Principles for Medical Research Involving Human Subjects. JAMA, 310, 2191-2194. https://doi.org/10.1001/jama.2013.281053

\section{Copyrights}

Copyright for this article is retained by the author(s), with first publication rights granted to the journal.

This is an open-access article distributed under the terms and conditions of the Creative Commons Attribution license (http://creativecommons.org/licenses/by/4.0/). 